OPEN

SUBJECT AREAS:

VOLCANOLOGY

MATERIALS SCIENCE

Received

24 January 2014

Accepted

8 July 2014

Published

28 July 2014

Correspondence and requests for materials should be addressed to M.P. (pompilio@ingv.

* Current address: Istituto Nazionale di Geofisica e Vulcanologia, Sezione di Palermo, Via Ugo La Malfa 153, 90146 Palermo, Italy.

\section{Identifying recycled ash in basaltic eruptions}

\author{
Claudia D’Oriano'*, Antonella Bertagnini' , Raffaello Cioni² \& Massimo Pompilio'
}

${ }^{1}$ Istituto Nazionale di Geofisica e Vulcanologia, Sezione di Pisa, Via della Faggiola 32, 56126 Pisa, Italy, ${ }^{2}$ Dipartimento di Scienze della Terra, Via G. La Pira 4, 50121 Firenze, Italy.

Deposits of mid-intensity basaltic explosive eruptions are characterized by the coexistence of different types of juvenile clasts, which show a large variability of external properties and texture, reflecting alternatively the effects of primary processes related to magma storage or ascent, or of syn-eruptive modifications occurred during or immediately after their ejection. If fragments fall back within the crater area before being re-ejected during the ensuing activity, they are subject to thermally- and chemically-induced alterations. These 'recycled' clasts can be considered as cognate lithic for the eruption/explosion they derive. Their exact identification has consequences for a correct interpretation of eruption dynamics, with important implications for hazard assessment. On ash erupted during selected basaltic eruptions (at Stromboli, Etna, Vesuvius, Gaua-Vanuatu), we have identified a set of characteristics that can be associated with the occurrence of intra-crater recycling processes, based also on the comparison with results of reheating experiments performed on primary juvenile material, at variable temperature and under different redox conditions.

I extural and morphological features of pyroclasts generated during explosive eruptions represent the first order source of information for eruption and fragmentation mechanisms, since the inner part of active craters, conduits and sub-volcanic systems cannot be directly accessed. The identification of the nature/ origin of the products of an explosive eruption is thus the first and most critical step for defining and quantifying the processes that occur before, during and immediately after an eruption (i.e. magma evolution, degassing, ascent, crystallisation, fragmentation and alteration). Volcanic ash is always present in the products of explosive activity, and it may be easily recovered during the eruption monitoring, from both proximal and distal sites, whatever the intensity of the activity. For this reason, in the recent years, studies on morphology and texture of volcanic ash have been increasingly used to derive indirect information on eruption dynamics, from both past and on-going eruptions ${ }^{1-4}$.

Pyroclasts can be roughly grouped in two categories ${ }^{5}$ : (1) juvenile, derived from the explosive disintegration of newly erupted magma; and (2) lithic, derived from erosion, shattering or engulfment of rocks or sediments that host the volcanic system. Juvenile material records in its variability the texture and composition of the complex pre- and syn-eruptive magma changes, whether they are the results of the fragmentation of an intrinsically heterogeneous magma body, or the effects of syn-eruptive modifications of the magma immediately after expulsion into the atmosphere ${ }^{6}$. For low- to mid-intensity basaltic eruptions, the largely preponderant juvenile ash is typically distinguished into two end-members: tachylite fragments, microlite-rich and poorly vesicular, and sideromelane ash, glassy and variably vesicular ${ }^{7}$. For these eruptions, lithic material derived from the fragmentation of pre-existing rocks generally represents only a minor proportion of the total erupted material. The relative proportions of different types of fragments have been often used to interpret eruption dynamics. Hence, the recognition of the variability of the juvenile material is crucial to the correct interpretation of eruptive and magmatic dynamics and kinetics.

Syn-eruptive recycling of pyroclasts may be an additional important process generating textural and compositional modifications of the ash, especially during small scale, long-lasting, pulsatory eruptive activity (Vulcanian, Surtseyan, Strombolian, up to Violent Strombolian eruptions). In this type of activity, a large amount of juvenile material (of different size) ejected during single explosions fall back into the crater area, becoming available for being incorporated and expelled again during the following activity, also during the same erup$\operatorname{tion}^{1,8-10}$ (Fig. 1a). The eruption mixture thus consists both of new fragmented juvenile material and of clasts, with the same composition, ejected during the preceding phases of the eruption, which had fallen back into the crater area and were reincorporated in the erupting mixture. We will refer to this latter type of material as "recycled clasts". The direct recognition of the different origin of juvenile vs. recycled fragments is often not straightfor- 

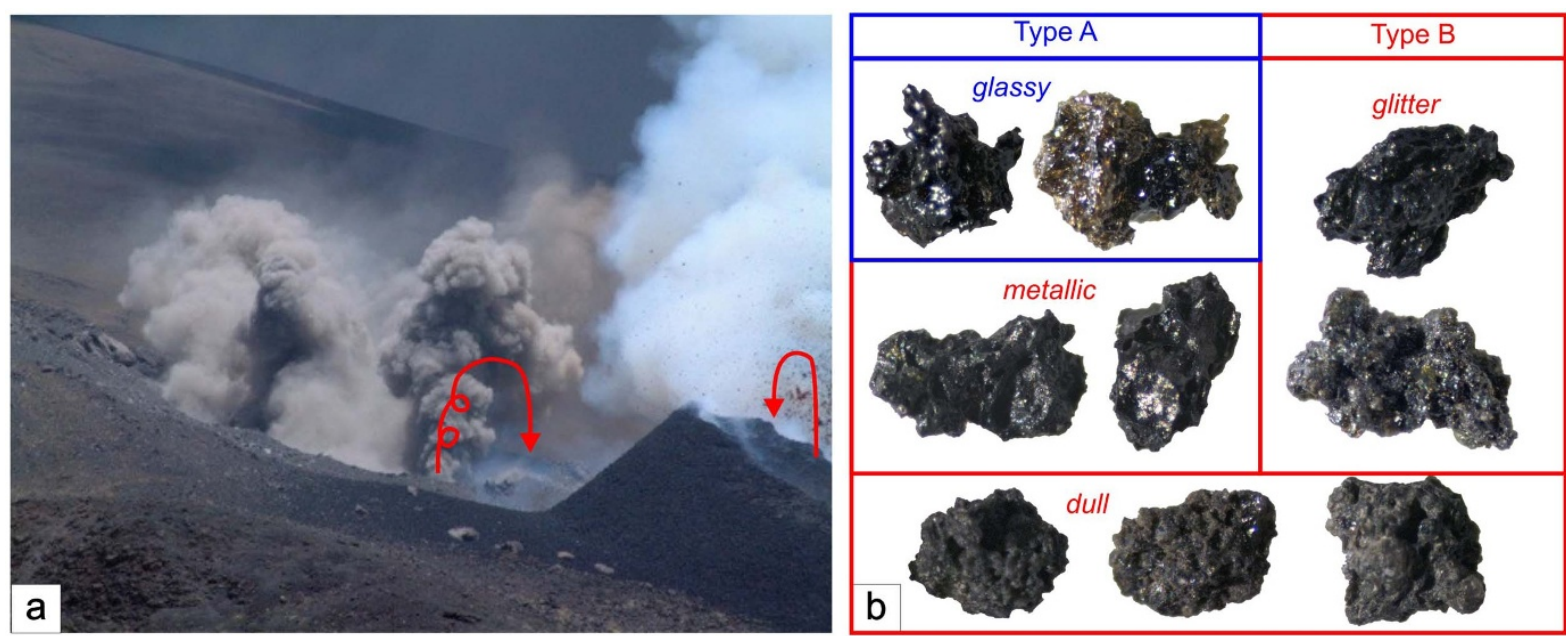

Figure 1 Example of mid-intense explosive activity and ash clast types. (a) Ash emission activity at Etna, during the 2001 eruption, with clear evidence of fragmented material falling back within the eruptive fissure, and that can be potentially recycled (Photo: Massimo Pompilio); (b) Binocular microscope picture of ash types, in the size range $0.5-1 \mathrm{~mm}$. Clasts representative of Type A and Type B groups.

ward, as they may share similar composition and external shape. However, we suggest that intra-crater recycling may induce changes in the primary features of the juvenile fragments, and that these changes represent a possible source of such a large variability often observed in the erupted material. To date, recycled clasts have been only occasionally detected but not described in detai ${ }^{1,8-10}$, and their role and abundance in some eruptions have been possibly underestimated.

Detailed investigation is needed in order to correctly interpret the role, the amount and the origin of each different type of ejected particles. In fact, the recognition of the real amount of the juvenile material ejected during each phase of the eruption, and of its composition and texture, are crucial to estimate the net energy release and the magma history.

In the following, we provide descriptions of the morphological and textural features of juvenile ash clasts emitted during selected midintensity eruptions at four basaltic volcanoes, and we identify some specific characteristics, which are common to all the studied products, and can be related to the effects of intra-crater, syn-eruptive recycling of juvenile fragments.

We focus on the ash-sized fraction because: a) it is rapidly quenched in air during trajectory between the vent and the sampling site, preserving its original textural and compositional features; $b$ ) the observation of the ash fraction provides a statistically reliable sample of the whole variability of fragmented material; c) it represents the portion of eruptive mixture that can be easily sampled during volcanic activity, as demonstrated by the monitoring protocols in use at frequently erupting volcanoes ${ }^{7}$.

Agents of clasts modification. Clasts falling back in active crater can be modified by mechanical, chemical (alteration - oxygen, sulphur, acid gases, water) and thermal agents, or by a combination of them.

Post-fragmentation modifications of recycled juvenile fragments have been described for a phreatomagmatic event, and some criteria for recognition were proposed based on vesicularity, morphology and occurrence of mud coatings $s^{8}$. The two main types of mechanically induced variations that are effective during recycling are clast fracture and abrasion. Laboratory investigations have also shown that the main mechanically-induced modifications of coarse pumice clasts are rounding and comminution ${ }^{12,13}$. While no experimental data are available for these effects on ash material, they are probably reduced by the lower inertia.

Chemical alteration acts mainly on the surface of pyroclasts, and it is largely effective also on fine-grained fragments, due to their high specific area. Alteration affects the few nanometres of the most external portion of the clasts ${ }^{14}$, and may range from ash surface acid dissolution, to salt deposition or encrustation, to exfoliation ${ }^{11,14}$. Exposure of glassy material to volcanic gases results also in the modification of the bulk composition of the external glass, and becomes significant after a few-days-long residence even at ambient temperatures ${ }^{11}$. While chemical alteration of the clasts induced by the magmatic fluids present in the eruptive plume can occur at largely variable temperatures, mainly depending on the position within the column ${ }^{14,15}$, chemical alteration related to syn-eruptive intra-crater residence always occurs at high temperature conditions. Therefore, clasts undergoing syn-eruptive recycling are possibly subject to both chemically and thermally-induced modifications.

Thermal alteration is particularly important when clasts are recycled within the crater area. Thermal modifications of pyroclasts were experimentally investigated ${ }^{16}$, simulating the effects of recycling by exposing natural primary basaltic pyroclasts in a furnace at temperatures variable from that of the glass transition $\left(\mathrm{T}_{\mathrm{g}} \approx 670-690^{\circ} \mathrm{C}\right)$ to the eruptive temperature $\left(T_{e} \approx 1090-1130^{\circ} \mathrm{C}\right)$, for different durations (up to 12 hours) and redox conditions. The observed large variety of modifications encompasses groundmass crystallisation and change in matrix glass composition, softening, sintering and welding of clasts, vapour-phase precipitation on external surfaces, colour and shape surface changes, up to subsolidus transformation of some mineral phases. Experimental results ${ }^{16,17}$ also show that thermal effects are poorly significant at temperatures lower than $T_{g}$, because the glassy structure does not relax and the kinetic of crystallisation is very slow. Similarly, at temperature close to $\mathrm{T}_{\mathrm{e}}$, melting of groundmass microlites starts, together with homogenization of glass composition, often resulting in the reset of the previous thermal history ${ }^{16,17}$.

\section{Methods}

Juvenile ash considered in this study was collected from mid-intensity explosive eruptions of generic "basaltic" composition and characterised by pulsatory dynamics In particular, we concentrated on ash grains selected from: a) falling-ash collected during an intense phase of ash forming explosive activity at Mt. Etna on 28-29/10/ $2002^{19}$; b) ash ejected during a weak explosion from the New South-East Crater (NSEC) of Etna on 24/09/2013 during the reactivation of the crater after a 5 months long quiescence (ingv-ct weekly report); c) ash from a series of mild Strombolian explosions at Stromboli occurred on September 2008 ${ }^{1}$; c) the deposits of continuous ash emission activity at Vesuvius from the "Santa Maria cycle" (SMM; II-IV century $)^{20}$ and the Middle Age ASla eruptions ${ }^{2}$, respectively; d) ash material erupted during the 2009 eruption crisis at Gaua Volcano (Vanuatu). Samples at Stromboli, Etna and Gaua were collected during the activity or a few days later. The products of the two well known historic eruptions of Vesuvius were chosen in order to extend the 



Figure $2 \mid$ Selected Type B fragments. SEM images of clasts with different external morphology, varying from irregular (a), to fluidal (b, c) and blocky (d). Arrows in (c) highlight cracks and wrinkles on external surface. Stereomicroscope image (e) of Type B clasts with different colours; (f) detail of the external surface of the clast shown in (a); (g) close-up of the area outlined in (b). The right part of the picture was captured in secondary electrons (SE) mode, while the left part records backscattered electrons (BSE); (h) enlargement of the inset in (d).

study to the tephra of past eruptions, where the uncertainties in the identification of the juvenile material (primary and recycled) can be also biased by the longer exposure to atmospheric agents and pedogenic weathering.

Collected samples were sieved, and few grams in the size range $0.5-1 \mathrm{~mm}$ were observed under the binocular microscope for component analysis, and with a scanning electron microscope (SEM) for morphoscopic and textural investigations. Total grain size distribution of mid-intensity basaltic explosive eruptions is generally centred on this class size ${ }^{21,22}$. This size class also represents the best compromise between the representativeness of the groundmass textural features of erupted magma (clast size is at least one order of magnitude larger than average size of groundmass microlites) and the possibility to capture the internal heterogeneity of the magma (by studying an adequate number of clasts).

Component analysis was performed by separating under the binocular microscope the juvenile particles from lithics and crystals. Relative precision of component percentages is $10 \%$ based on three replicates of 100 particle count performed by two different operators.

A number of 30 ash fragments for each component was then characterized at SEM, basing on overall shape, vesicularity, surface morphology and groundmass texture, following ${ }^{23}$. For the definition of terms used in the description of the clast surface (luster, colour, aspect) we refer to terms defined in the Mineral Identification Key section of the Mineralogical Society of America (website). The luster corresponds to the overall sheen of ash surface, not to be confused with its colour. External surfaces can have the sheen of polished metal (METALLIC LUSTER), or that of an unpolished metal pitted by weathering (GLITTER), or it may have the sheen of glass (GLASSY), or may have an opaque surface (i.e DULL) (Fig. 1b).

\section{Results}

As typical of mid-intensity basaltic eruptions, the lithological features of the studied juvenile material are largely variable $e^{2,3,7,23}$. For convenience, we grouped the juvenile components of each studied sample into two different classes. Fragments with clearly juvenile, glassy features were named Type A, and the fragments with variably crystallised external surfaces and groundmasses were named Type B (Fig. 1b).

Type A clasts are similar for the different volcanoes, being characterized by glassy external surfaces, generally free of vapour-phase condensates, secondary minerals or adhering dust. The outlines of Type A clasts are largely variable from spiny (due to the intersection of bubbles with the external surfaces) to fluidal, with smooth external surfaces (Fig. 1b). Irrespective of the eruption or volcano, Type A clasts are present both as light brown, highly vesicular clasts, and as dark brown, scoriaceous clasts, with larger bubbles and septa. The matrix glass is optically homogeneous and shows a uniform grey level in back-scattered electronic (BSE) images (Supplementary Fig. S1 online). Groundmass is generally hypohyaline, with mainly rounded bubbles and variable amounts of euhedral microlites, possibly related to degassing-induced crystallisation of magma before fragmentation. Type A clasts closely match the distinguishing features given for sideromelane fragments ${ }^{3,7}$ and then we interpret these clasts as primary juvenile material, not modified successively.

Type B clasts have the same external shape of Type A clasts, and, in some cases (5-10 vol\%), show bevelled edges (totally absent in type A) due to abrasion processes. External surfaces range from irregular (Fig. 2a) to smooth (Fig. 2b,c) and curviplanar (Fig. 2d), with bubble walls of variable thickness. A large part (30-40 vol\%) has a composite surface, with the presence of fluidal and spiny portions in the same clast. An important distinguishing feature from Type A clasts is the wide range of colour gradation of the external surface, from yellow, honey, light-brown to grey, black, dark-brown to orange to red (Figs. 1b; 2e). Surface colour is sometimes inhomogeneous, and its variations can be limited to the bubble rims or is pervasive over the entire surface of the clast. Surfaces can be dull, or can display a metallic luster and glittering (Fig. 1b). The metallic luster can be present with different intensity on clasts of different colour and it is more intense on smooth surfaces. SEM images show that the external surfaces for the majority $(\sim 80$ vol\%) of Type B clasts have various degrees of alteration/modification, and differ from the primary surfaces of Type A clasts for the presence of wrinkles (Fig. 2c), cracks (Fig. 2c, f), flakes or exfoliations (Fig. 2g). Tiny mounds project above the clast surface, possibly related to nuclei of groundmass crystallisation (Fig. 2h). In some cases, the presence of adhering dust and vapour-phase sublimates (Fig. 2f) partially hides primary morphologic features. The whole vesicularity is generally lower with respect to Type A clasts, and bubbles are sometimes collapsed, deformed and lined by oxides (Fig. 3a, b). The groundmass texture of Type B clasts varies from glassy to holocrystalline, with a wide range of crystallinity. BSE images show that crystallinity is often not homogeneous, showing very fine grained ( $<10$ micron) crystal-rich portions coexisting with glassy areas (Fig. 3c). About $50 \%$ of the 



Figure 3 BSE-SEM images of groundmass textures in Type B fragments. (a) and (b) clasts showing high crystallinity, reduced vesicularity and collapsed bubbles; (c) inhomogeneous distribution of microlites in glassy groundmass; (d) spherulites and plumose texture of microlites; plagioclase crystals lined by oxides; (e) external portion of a clast, showing interface controlled growth of Fe-oxides microlites; (f) crystal-rich groundmass texture. Olivine and Ti-mag show subsolidus transformation and lamellae texture, respectively.

clasts has a groundmass characterized by scattered spherulites, dendritic or plumose crystallites (Fig. 3d). In these cases, groundmass is characterized by massively crystallised fine-grained areas coexisting with more scattered, faceted and coarser microlites $(>20$ micron) (Fig. 3). When present, dendritic crystals of oxides are generally limited to the most external portion (Fig. 3e). Often, microphenocrysts and microlites have a continuous oxidized rim (Fig. 3b,d,f). For their overall features, a large part of Type B clasts strictly resembles the tachylite clasts ${ }^{7}$.

Surface luster of the clasts is strictly correlated to groundmass texture. In particular, metallic luster is associated with the presence of abundant crystal nuclei and microlites along the clast surface (rim). Conversely, massively crystallised groundmass is associated with the presence of an external crust, giving a dull luster to the surface (Supplementary Figs. S2, S3 online).

Type B clasts show also subsolidus transformations of Timagnetite and olivine. Microphenocrysts of Ti-magnetite exhibit a symplectitic texture (complex intergrowths of minerals) that comprises lamellae exsolution of ilmenite and magnetite (Fig. 3f). Olivine microlites with alteration textures, characterized by adjacent lamellae of magnetite and pure forsterite, are sporadic, but do occur in Etna 2013 sample (Fig. 3f).

Component analysis (Table 1), performed using the binocular microscope, indicates that Type A clasts account for about 12 and 7 vol.\% for the Etna 2002 and 2013 samples, respectively; while they vary from 26 to 56 vol.\% for Vesuvius samples. Relative errors are $\approx 10 \%$. Type A clasts represent the majority of the clasts ( $>70 \mathrm{vol} . \%$ ) in samples from Stromboli and Gaua. Type B clasts account for the 60 vol.\% of the total components in Etna 2002 sample, 38 vol.\% for Etna 2013 sample, 34-46 vol.\% of the Vesuvius samples, and 5-
15 vol.\% of the total for Stromboli and Gaua samples, the rest being crystals or accessory lithics.

While Type A clasts represent magma clasts unmodified after fragmentation, we suggest that the large variability observed in Type B clasts can be the inheritance of magma heterogeneities existing in the magma column before fragmentation (large variability in microlite and bubble contents) or the results of the modification of juvenile clasts after the fragmentation. Hereafter, we will discuss about the different origin of the wide internal variability shown by Type B clasts, trying to distinguish between primary features indicating heterogeneity in the erupting magma, from features related to secondary modifications following clast recycling.

\section{Recycling of Juvenile Ash}

Features observed in the Type B clasts will be discussed in terms of the processes that occur during the eruption or during the intracrater recycling. We will pay particular attention to the crystallinity and the groundmass texture, to the relationships between groundmass crystallisation and surface properties of the clasts (luster, colour, texture), and to the meaning of subsolidus transformations in some mineral phases. As stated before, thermal processes are responsible of the largest and most pervasive post-fragmentation modifications. For this reason, the comparison of the natural variability of Type B clasts with the results of experimental reheating of clasts of comparable composition performed at variable $\mathrm{T}$ and redox conditions ${ }^{16,17}$ appears to be extremely useful.

Crystallinity. First of all, we totally exclude the notion that crystal nucleation and growth is related to quenching during the ejection (both for type A and B clasts). In fact, at a reasonable quench rate of 


\begin{tabular}{|c|c|c|c|c|c|c|c|c|c|}
\hline $\begin{array}{l}\text { Volcano } \\
\text { Sample }\end{array}$ & $\frac{\text { GAUA }}{\text { Gaua2009 }}$ & EST1 & EST4 & EST8 & EST14 & EP2 & VSM9 & 2002 (sigma) & 2013 \\
\hline n. of clasts & 348 & 100 & 100 & 100 & 100 & 100 & 100 & 100 & 265 \\
\hline Type A (\%) & 86 & 90 & 97 & 86 & 90 & 56 & 26 & 12 & 7 \\
\hline Type B (\%) & 7 & 6 & 3 & 14 & 3 & 34 & 46 & 62 & 38 \\
\hline \multicolumn{10}{|c|}{$\begin{array}{l}\text { Notes: } \\
\text { Gaua2009 sample corresponds to the ash material collected at Gaua Volcano (Vanuatu) in } 2009 \text {; } \\
\text { EST1/4/8/14 consist of ash samples from Stromboli Volcano collected on } 2008 \text { in the time frame of one week; } \\
\text { EP2 represents the base of the ASla eruption of Vesuvius; } \\
\text { VSM9 represents an ash bed produced during the SMM eruption of Vesuvius; } \\
\text { Sample } 2002 \text { is the ash emitted at Etna in the night between the } 28 \text { and } 29 \text { October 2002; } \\
\text { Sample } 2013 \text { is an ash sample collected at Etna on } 24 \text { September } 2013 \text {. }\end{array}$} \\
\hline
\end{tabular}

$20^{\circ} \mathrm{K} \mathrm{s}^{-124}$ for fine grained material and using the fastest feldspar growth rate of $10^{-6} \mathrm{~cm} \mathrm{~s}^{-125}$, a net growth of only 0.2 microns between $\mathrm{T}_{\mathrm{e}}$ and $\mathrm{T}_{\mathrm{g}}$ will occur. Therefore, microlites in the groundmass of studied clasts are assumed to reflect the response to cooling, or syn-eruptive degassing during magma ascent along the conduit $^{26,27}$. In this context tachylites, which contain a large amount of microlites, have been quite often associated with the slowly rising and crystallising magma along the margins of the conduit ${ }^{7}$.

Lab experiments ${ }^{16,17}$ have shown that reheating of primary, glassy, juvenile fragments, at high temperature, variable redox conditions and $\mathrm{P}=0.1 \mathrm{MPa}$, can induce the reactivation of the frozen melt (glass), accelerating the chemical and thermal diffusion, and volatile loss. As a general rule, temperature, redox conditions and increasing exposure time control the groundmass crystallisation. During reheating, groundmass crystallisation, revesiculation and cracking of external surfaces occur to restore a new equilibrium state.

Additional information on processes of heating/cooling-induced crystallisation comes from glass industry. Thermal treatment of previously formed glass is in fact a general method for inducing massive crystallisation in the glass in order to produce glass-ceramic. Also in this case, the temperature and duration of the heating process are the most important parameters that control crystal nucleation and growth. The reciprocal role of these parameters can be synthesized in a time-temperature transformation diagram (known as TTT diagram $)^{28}$. In this diagram the minimum dwelling time to induce crystallisation corresponds to a temperature $\mathrm{T}_{\mathrm{n}} \approx 0.8 \mathrm{~T}_{\text {liquidus }}$. Experiments of reheating, carried out at $\mathrm{P}=0.1 \mathrm{MPa}$ on glassy volcanic ash ${ }^{16}$ and on crushed lava fragments ${ }^{17}$, confirm that basaltic glass follows the same behaviour of industrial glass, but having a $\mathrm{T}_{\text {liquidus }}$ of $\approx 1250^{\circ} \mathrm{C}$ and a $\mathrm{T}_{\mathrm{n}}$ of $\approx 1000^{\circ} \mathrm{C}$, that broadly corresponds to the nose of the crystallisation field (Fig. 4). Incomplete degassing of glass containing a slight amount of dissolved volatiles $(\approx 0.6 \text { wt. } \%)^{17}$ entails a shift of the liquidus temperature toward higher values, of about few tens of degrees.

In Fig. 4, the thermal histories of clasts can be tracked as distinct trajectories possibly intercepting, at different temperatures, the area of massive crystallisation. Experimentally measured relationships between cooling rate and crystallisation demonstrated that melts quenched at high cooling rate $\left(>0.66^{\circ} \mathrm{C} \mathrm{sec}^{-1}\right)^{18}$ precipitate less than $5 \%$ of crystals. Thus we can infer that ash fragments quenched with comparable cooling rates preserve their original features and can be interpreted as primary juvenile clasts. Conversely, recycling of clasts at $\mathrm{T}$ between $700^{\circ} \mathrm{C}$ and $1100^{\circ} \mathrm{C}$ induces a variable extent of glass crystallisation, as a function of the temperature. Accordingly, in case of reheating, the amount of groundmass crystals could be used as a proxy for defining the heating temperature interval and duration of recycling processes.

Therefore we cannot exclude that oscillations in the feeding rate can favour the complete degassing of the magma, or that thermal fluctuations can permit the cooling of portions of magma close to the conduit walls. All these processes will induce an increase in crystallinity and heterogeneities in magma columns as those described in type B clasts.

As a result, groundmass crystallisation is a process that may occur under different conditions, which are effective both on the magma before fragmentation, and on the clasts during reheating related to intra-crater recycling. For these reasons we cannot consider the crystal content alone as diagnostic criterion for post-fragmentation ash recycling process.

Groundmass texture. Size and shape of microlites can be considered the main features to discriminate between the dominance of reheating (recycling) and/or crystallisation. Massive, pervasive to patchy nucleation of fine grained microlites ( $<10$ micron), sometimes with spherulitic or plumose shapes, indicates fast growth under high undercooling ${ }^{27}$, as that observed in reheating experiments, where kinetics of crystallisation in an already quenched, cold, glass-bearing particle is reactivated. Conversely, syn-eruptive (slower) cooling and/or degassing-controlled crystal growth will result in skeletal to faceted microlites of variable size (from few tens of microns) ${ }^{26,27}$. The large variability in textures of microlites and groundmass crystallinity observed in Type B clasts (Fig. 3) suggests the superimposition of both syn-eruptive and reheating-induced groundmass crystallisation.

The occurrence of microlites (mainly oxides) along pre-existing interfaces, such as clast surface, contacts between clasts, or the external surfaces of pre-existing crystals, is observed in both natural samples (Fig. 3d; Supplementary Fig.S2 online) and products of reheating experiments, performed in oxidizing environments. This is related to heterogeneous, interface controlled, nucleation and growth, and can be considered a clear indication of recycling.

Fe-oxides along rims of plagioclase microphenocrysts and microlites are a common feature observed in the groundmass of Type B clasts. Similar features have been observed in the products of a Violent Strombolian eruption, and were previously attributed to magma oxidation before fragmentation ${ }^{29}$. Despite this, experiments show that minerals rimmed by oxides, or by Fe-rich laths, commonly form in reheated clasts by heterogeneous nucleation under high oxidizing conditions and variable undercooling $\left(750^{\circ} \mathrm{C}<\mathrm{T}<\right.$ $\left.1050^{\circ} \mathrm{C}\right)^{16}$.

Surface properties. Properties of the external surface are the primary elements on which Type A and B juvenile clasts can be discriminated. These properties can be easily observed with a binocular microscope even after minimal sample treatment (ultrasound cleaning of a sample aliquot in order to remove adhering dust, when present).

Luster varies in type B clasts from metallic to dull, contrasting with the glassy surface of Type A clasts. In experiments, glassy clasts 


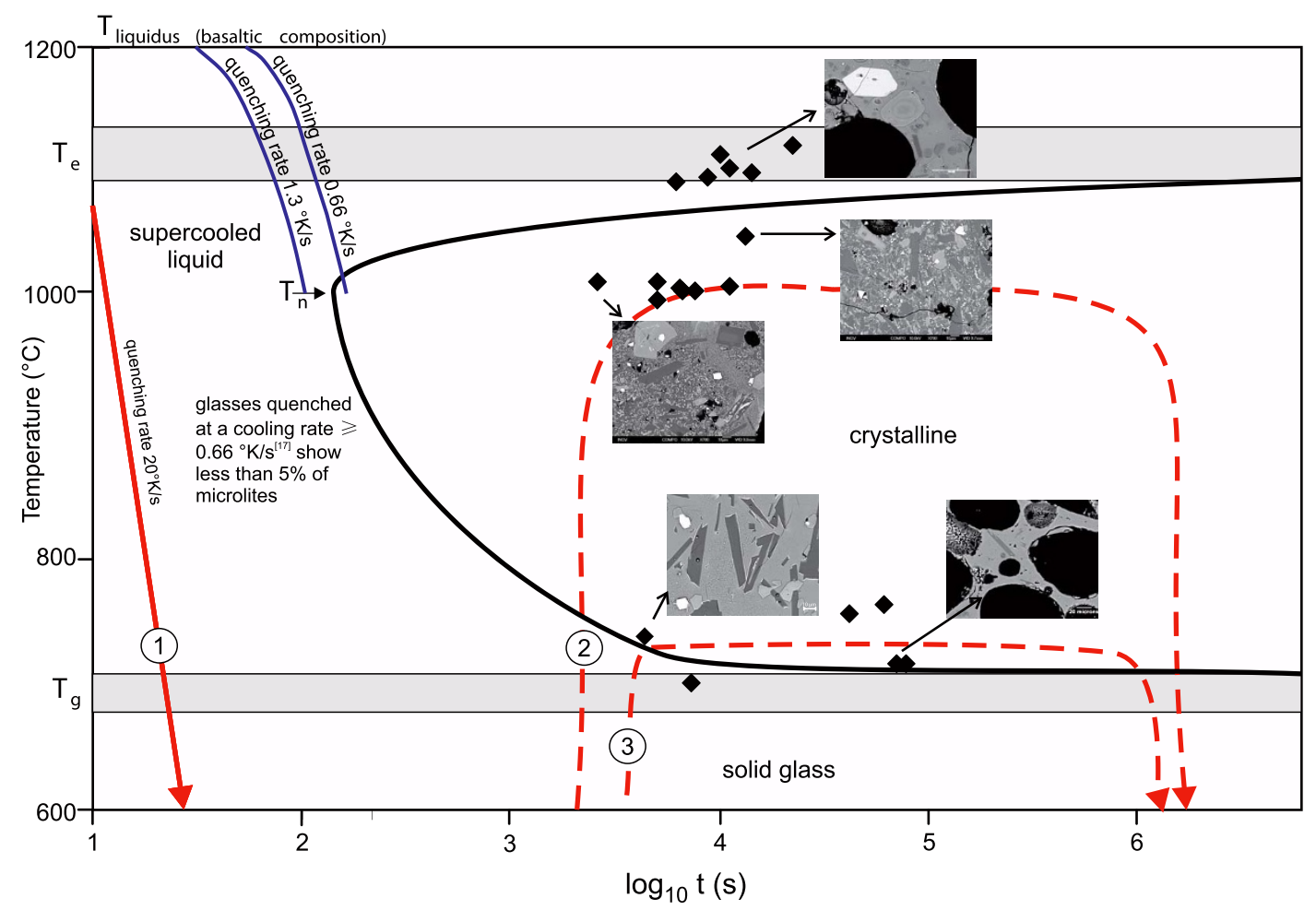

Figure 4 Time-temperature transformation diagram (known as TTT diagram), based on experimental results ${ }^{16,17}$. Diamonds correspond to the experiments reported $\mathrm{in}^{16}$. The black line separates the field of crystallisation (at its right) from that of unmodified glasses. The quenching rate of $1.3^{\circ} \mathrm{K} / \mathrm{s}$ and $0.66^{\circ} \mathrm{K} / \mathrm{s}$ have been extrapolated from results of quenching experiments ${ }^{17}$ and represent the slowest cooling rate at which glasses do not crystallise (less than $5 \%$ of microlites). $T_{n}$ is the temperature corresponding to the minimum dwelling time, for massive groundmass crystallisation at constant temperature. The fine black arrows indicate the groundmass texture of clasts reheated at corresponding temperature and time conditions. The red arrow number 1 simulates the rapid quenching of ash $\left(20^{\circ} \mathrm{K} / \mathrm{s}^{24}\right)$, that after fragmentation, fall outside the crater (no recycling). The paths 2 and 3 represent possible trajectories of ash recycled at high and low temperature, respectively.

developed a metallic luster after reheating at temperature between 700 and $750^{\circ} \mathrm{C}$, in oxidizing condition ${ }^{16}$.

Glitter results from the fine-grained crystallisation of the very external skin $(<5 \mu \mathrm{m})$ of the clast, and the newly formed microlites cluster into tiny mounds. We suggest that similar thermal (temperature close to $\mathrm{T}_{\mathrm{g}}$ ) and oxidizing conditions can be present at very shallow depth in the crater area, where the clasts filling the crater depression are in contact with the atmosphere.

Grains with a dull luster are associated with massive crystallisation of the whole groundmass; experimental clast reheating at low redox conditions and intermediate temperature $\left(700-1000^{\circ} \mathrm{C}\right)$ resulted in a similar texture. In such conditions, in fact, the glass devitrifies and crystallises, forming $\mu \mathrm{m}$-sized minerals, clearly visible as a continuous layer on the external surface. Alternatively, dulling of external surface occurred after $>1$ hour of exposure to volcanic gases, thus promoting the development of an altered external portion ${ }^{11}$. These two processes are difficult to distinguish only with a macroscopic inspection of the clast surface, but can be easily detected looking at polished sections of the clasts, since the above described massive groundmass crystallisation is only produced during reheating.

The colour of the external surface of the clasts depends on glass amount, composition and vesicularity. The colour of Type B clasts is extremely variable, from black to grey to orange-red. Although orange-red clasts are poorly represented in Type B clasts, they are ubiquitous in all sample sets. Reheating experiments showed that surface reddening could result from crystallisation of Fe-bearing phases on the external surfaces, in oxidizing conditions. Experiments also revealed that intense reddening occurs over a short time scale (in the order of an hour) at $\mathrm{T}>700^{\circ} \mathrm{C}$ and in the presence of air, indicating that this feature is not necessarily the result of long lasting alteration processes, but it can be rapidly acquired during intra-crater recycling. The recognition of juvenile material reddened by syneruptive thermal effects is important, as red clasts can be erroneously interpreted as lithic material (lava fragments) affected by hydrothermal alteration.

External surfaces of Type B clasts are in some cases weakly sintered, showing smoothed shapes and newly-formed vesicles. Experiments ${ }^{16}$ performed in presence of air indicated that, at low temperature, crystallisation prevailed over sintering, while at lower $\mathrm{fO}_{2}$ a weak softening of external surfaces was observed, causing sintering of contact surfaces and the formation of microwrinkles on the external, glassy surfaces. Softening and microwrinkling of the external surface, as those recognizable in some clasts from the Etna 2013 sample (Fig. 2c), are thus a clear indication of recycling.

Subsolidus modifications of minerals. Subsolidus transformation of pre-existing olivine and oxides is a well-known process that indicates alteration under high temperature and oxidizing conditions $^{30,31}$. Trellis-textures in oxides have been reproduced in experiments at $\mathrm{T}>700^{\circ} \mathrm{C}$ in oxidizing conditions ${ }^{16}$. Experiments also indicated that olivine modification occurs at $\mathrm{T}>1000^{\circ} \mathrm{C}$, and is substantially absent in the low temperature range $\left(700-750^{\circ} \mathrm{C}\right)$, possibly a kinetic effect due to short run times unable to complete the reaction. Similar textures have been reported also in the literature ${ }^{29,32,33}$, focused on different products, including Strombolian scoriae, lavas, and angular blocks representing inner portions of the crater zone, and have been interpreted either as processes occurring within the magmatic column (fast change in $\mathrm{fO}_{2}$ ), or as related to the exposure at high temperature in oxidizing conditions. 
In the ash samples analysed in the present study, these features are present but not ubiquitous and mainly affect oxides. We assert that subsolidus transformations can be also related to recycling, but these effects are strongly dependent on time and temperature of exposure.

\section{Conclusive Remarks and Volcanological Implications}

We suggest here that clast recycling in the intra-crater area can induce important morphological and textural changes on juvenile material falling back in the crater during oscillatory explosive activity, and that in some cases a large amount of juvenile-like material results from thermally-induced modifications during intra-crater recycling. During intra-crater recycling clasts acquire distinctive features that comprise a change in colour, a loss of glassy luster and crystallisation of groundmass. The extent of groundmass crystallisation and external appearance are strictly related. In particular, glittering is associated with the incipient, non-pervasive crystallisation of the groundmass that becomes visible as tiny mounds on the surface or isolated microcrystals. Dulling appears when crystallisation proceeds and extends to the whole grain. The transition between these features is related to the time of exposure at high $\mathrm{T}$ conditions and thus to the timescale of recycling. We have shown that these diagnostic features can be a very important tool to avoid misinterpretations and inaccurate estimates of eruptive style and intensity.

It is also worth underlining that the recognition of the occurrence and extent of recycling processes has important volcanological implications, considering that:

juvenile clasts with a microlite-rich groundmass have often been classified as tachylites, and as the result of degassing-related crystallisation of a slowly ascending magma column or plug, with important implications for the interpretation of magma ascent and fragmentation dynamics;

neglecting the effects of clast recycling might result in an erroneous overestimation of the juvenile material participating in a given explosion/eruptive pulse, and hence to the definition of total mass (Magnitude), total amount of volatiles released by the ejected magma, and energy flux (mass flow rate, thermal energy) associated with the eruption;

the misrecognition in some cases of recycled clasts as lithic clasts (for example clasts with a highly oxidized, reddened surface) might lead to overestimation of the role of syn-eruptive erosion of crater walls, or the involvement of phreatic water or hydrothermal fluids into the eruption dynamics.

The recognition of an important amount of syn-eruptively recycled clasts suggests that crater infilling by recycled magmatic debris should be considered in the dynamics of some oscillatory eruptive styles, as this infilling may affect strength and permeability of the top of the magmatic column, indirectly controlling eruption explosivity ${ }^{10}$.

Concluding, we believe that the correct identification of the recycling processes is worthwhile during the routine monitoring of volcanic activity, becoming crucial for the evaluation of eruptive scenarios and hazard assessment during the early phases of an eruptive crisis. For these reasons we are also convinced that the use of the proposed diagnostic features should be largely included within best practices for volcano monitoring.

1. D'Oriano, C., Bertagnini, A. \& Pompilio, M. Ash erupted during normal activity at Stromboli (Aeolian Islands, Italy) raises questions on how the feeding system works. Bull. Volcanol. 73, 471-477 (2011).

2. D'Oriano, C., Cioni, R., Bertagnini, A., Andronico, D. \& Cole, P. D. Dynamics of ash-dominated eruptions at Vesuvius: the post-512 AD AS1a event. Bull. Volcanol. 73, 699-715 (2011)

3. Heiken, G. \& Wohletz, K. H. Volcanic Ash (California Univ. Press, Berkeley, 1985).
4. Taddeucci, J., Pompilio, M. \& Scarlato, P. Conduit processes during the JulyAugust 2001 explosive activity of Mt. Etna (Italy): inferences from glass chemistry and crystal size distribution of ash particles. J. Volcanol. Geotherm. Res. 137, 33-54 (2004).

5. White, J. D. L. \& Houghton, B. F. Primary volcaniclastic rocks. Geology 34 677-680 (2006).

6. Houghton, B. F. \& Gonnerman, H. M. Basaltic explosive volcanism: constraints from deposits and models. Chemie der Erde 68, 117-140 (2008).

7. Taddeucci, J., Pompilio, M. \& Scarlato, P. Monitoring the explosive activity of the July-August 2001 eruption of Mt. Etna (Italy) by ash characterization. Geophys. Res. Lett. 29, 1230, doi: 10.1029/2001GL014372 (2002).

8. Houghton, B. F. \& Smith, R. T. Recycling of magmatic clasts during explosive eruptions: estimating the true juvenile content of phreatomagmatic volcanic deposits. Bull. Volcanol. 55, 414-420 (1993).

9. De Rosa, R. Compositional modes in the ash fraction of some modern pyroclastic deposits: their determination and significance. Bull. Volcanol. 61, 162-173 (1999).

10. Patrick, M. R., Harris, A. J. L., Ripepe, M., Dehn, J., Rothery, D. A. \& Calvari, S. Strombolian explosive styles and source conditions: insights from thermal (FLIR) video. Bull. Volcanol. 69, 769-784 (2007).

11. Spadaro, F., Lefèvre, R. \& Ausset, P. Experimental rapid alteration of basaltic glass: implications for the origins of atmospheric particulates. Geology. 30, 671-674 (2002).

12. Cagnoli, B. \& Manga, M. Pumice-pumice collisions and the effect of the impact angle. Geophys. Res. Lett. 30, 1636, doi:10.1029/2003GL017421 (2003).

13. Manga, M., Patel, A. \& Dufek, J. Rounding of pumice clasts during transport: field measurements and laboratory studies. Bull. Volcanol. 73, 321-333 (2010).

14. Delmelle, P., Lambert, M., Dufrêne, Y., Gerin, P. \& Óskarsson, N. Gas/aerosol-ash interaction in volcanic plumes: New insights from surface analyses of fine ash particles. Earth Planet. Sc. Lett. 259, 150-170 (2007).

15. Óskarsson, $\mathrm{N}$. The interaction between volcanic gases and tephra: fluorine adhering to tephra of the 1970 Hekla eruption. J. Volcanol. Geotherm. Res. 8, 251-266 (1980).

16. D’Oriano, C., Pompilio, M., Bertagnini, A., Cioni, R. \& Pichavant, M. Effects of Experimental Reheating at Different Temperatures and Redox Conditions of Natural Basaltic Ash. Contrib. Mineral. Petr. 165, 863-883 (2013).

17. Applegarth, L. J., Tuffen, H., James, M. R., Pinkerton, H. \& Cashman, K. V. Direct observations of degassing-induced crystallization in basalts. Geology 41, 243-246 (2014).

18. Applegarth, L. J., Tuffen, H., James, M. R. \& Pinkerton, H. Degassing-driven crystallization in basalts. Earth Sci. Rev. 116, 1-16 (2013).

19. Andronico, D., Cristaldi, A., Del Carlo, P. \& Taddeucci, J. Shifting styles of basaltic explosive activity during the 2002-03 eruption of Mt. Etna, Italy. J. Volcanol. Geotherm. Res. 180, 110-122 (2009).

20. Cioni, R., D’Oriano, C., Bertagnini, A. \& Andronico, D. The IInd to IVth century explosive activity of Vesuvius: the prelude to the subplinian AD 472 eruption. Ann. Geophys 56, S0438, doi: 10.4401/ag-6444 (2013).

21. Andronico, D., Cristaldi, A. \& Scollo, S. The 4-5 September 2007 lava fountain at South-East Crater of Mt Etna, Italy. J Volcanol Geotherm Res. 173, 325-328 (2008).

22. Andronico, D., Scollo, S., Caruso, S. \& Cristaldi, A. The 2002-03 Etna explosive activity: Tephra dispersal and features of the deposits. J. Geophys. Res. 113, B04209 (2008).

23. Cioni, R., D'Oriano, C. \& Bertagnini, A. Fingerprinting ash deposits of small scale eruptions by their physical and textural features. J. Volcanol. Geotherm. Res. 177, 277-287 (2008)

24. Xu, Z. \& Zhang, Y. Quench rates in air, water, and liquid nitrogen, and inference of temperature in volcanic eruption columns. Earth Planet. Sci. Lett. 200, 315-330 (2002).

25. Agostini, C., Fortunati, A., Arzilli, F., Landi, P. \& Carrol, M. R. Kinetics of crystal evolution as a probe to magmatism at Stromboli (Aeolian Archipelago, Italy). Geochim Cosmochim Acta 110, 135-151 (2013).

26. Hammer, J. E., Cashman, K. V. \& Voight, B. Magmatic processes revealed by textural and compositional trends in Merapi dome lavas. J. Volcanol. Geotherm. Res. 100, 165-192 (2000).

27. Hammer, J. E. \& Rutherford, M. J. An experimental study of the kinetics of decompression-induced crystallization in silicic melt. J Geophys Res. 107, 2021, doi: 10.1029/2001JB000281 (2002).

28. Le Bourhis, E. Glass (Wiley-VCH, Verlag GmbH \& Co. KGaA, Weinheim, 2008).

29. Genareau, K., Valentine, G. A., Moore, G. \& Hervig, R. L. Mechanisms for transition in eruptive style at a monogenetic scoria cone revealed by microtextural analyses (Lathrop Wells volcano, Nevada, U.S.A.). Bull.Volcanol. 72, 593-607 (2010).

30. Haggerty, S. E. \& Baker, I. The Alteration of Olivine in Basaltic and Associated Lavas Part I: High Temperature Alteration. Contrib. Mineral. Petr. 16, 233-257 (1967).

31. Haggerty, S. E. Oxide textures; a mini-atlas. Rev. Mineral. 25, 129-192 (1991).

32. Del Moro, S., Renzulli, A., Landi, P., La Felice, S. \& Rosi, M. Unusual lapilli tuff ejecta erupted at Stromboli during the 15 March 2007 explosion shed light on the nature and thermal state of rocks forming the crater system of the volcano. J. Volcanol. Geotherm. Res. 254, 37-52 (2013). 
33. Cortés, J., Wilson, M., Condliffe, E. \& Francalanci, L. The Occurrence of Forsterite and Highly Oxidizing Conditions in Basaltic Lavas from Stromboli Volcano, Italy. J. Petr. 47, 345-1373 (2006).

\section{Acknowledgments}

Work was funded by MIUR-PRIN 2008, AshErupt- UR 20083MC8W2_003. CD was supported in the framework of INGV-DPC convention 2012-13-V1.

\section{Author contributions}

A.B., R.C., C.D. and M.P. sampled and selected the ash material. C.D. prepared the samples, performed SEM inspection and draft figures. A.B., R.C., C.D. and M.P. discussed and interpreted together all collected data and wrote the manuscript.

\section{Additional information}

Supplementary information accompanies this paper at http://www.nature.com/ scientificreports

Competing financial interests: The authors declare no competing financial interests.

How to cite this article: D’Oriano, C., Bertagnini, A., Cioni, R. \& Pompilio, M. Identifying recycled ash in basaltic eruptions. Sci. Rep. 4, 5851; DOI:10.1038/srep05851 (2014).

(c) (i) (-) This work is licensed under a Creative Commons Attribution-NonCommercial-

cc. NoDerivs 4.0 International License. The images or other third party material in this article are included in the article's Creative Commons license, unless indicated otherwise in the credit line; if the material is not included under the Creative Commons license, users will need to obtain permission from the license holder in order to reproduce the material. To view a copy of this license, visit http:// creativecommons.org/licenses/by-nc-nd/4.0/ 